\title{
AC 2008-1187: DEVELOPMENT OF A CAE COURSE PROJECT FOCUSING ON PROJECT DATA MANAGEMENT AND VIRTUAL PROTOTYPING THROUGH FEA OF WINDSHIELD WIPER SYSTEM DESIGN
}

\section{Yaomin Dong, Kettering University}

Dr. Yaomin Dong is Assistant Professor of Mechanical Engineering at Kettering University. He received his Ph.D. in Mechanical Engineering at the University of Kentucky in 1998. Dr. Dong has extensive R\&D experience in automotive industry and holds multiple patents. He is specialized in metalforming processes, design with composite materials, and finite element analysis.

\section{Arnaldo Mazzei, Kettering University}

Dr. Arnaldo Mazzei is an Associate Professor of Mechanical Engineering at Kettering University. He received his Ph.D. in Mechanical Engineering from the University of Michigan in 1998. He specializes in dynamics and vibrations of mechanical systems and stability of drivetrains with universal joints. His current work relates to modal analysis, stability of drivetrains, finite element analysis and CAE. He is a member of ASME, ASEE and SEM.

\section{Paul Zang, Kettering University}

Dr. Paul Zang is a Professor of Mechanical Engineering at Kettering University and a certified Professional Engineer in the State of Michigan. Professor Zang's research is in the area of Computer Aided Engineering and Manufacturing. He is the Group Leader for the PLM World Academic Focus Group, a selection of academic institutions throughout the world. He is also the PACE Program Coordinator for Kettering University. Dr. Zang has consulted with Rockwell Automotive, Meritor, Ford Motor Company and General Motors 


\title{
Development of a CAE Course Project Focusing on Project Data Management and Virtual Prototyping through FEA of Windshield Wiper System Design
}

\begin{abstract}
Computer Aided Engineering (CAE) has been a core course for Junior 1 Mechanical Engineering students at Kettering University for more than a decade. This paper presents an approach to develop a new team project for the CAE course. The approach addresses Project Data Management (PDM) through an automotive windshield system design and analysis. The purpose of the course project is to learn how to manage teams and the voluminous amounts of data when working on assemblies and their related parts. Automotive windshield wiper systems are used in vehicles to remove contaminants such as rain, sleet, snow and dirt from the windshield. A typical wiper system consists of an electric motor, a linkage mechanism to transform rotational motion from the motor to oscillatory motion and a pair of wiper arms and blades. Such an assembly is representative in terms of complexity for a mechanical system and therefore ideal for this level of student as a course project. Each project team sets up a "configured project" including Roles, States, Approval Process, Library and Cataloge. Each team member is responsible for several parts design and/or analysis. The design and PDM parts of the project have been discussed by the authors in a previous work ${ }^{[1]}$. In order to meet the engineering specifications, the wiper system design must be validated for functional performance and safety. Here the Finite Element Analysis (FEA) of the wiper system will be used as a virtual prototyping and design tool.
\end{abstract}

\section{Introduction}

Computer Aided Engineering, often referred as CAE, is the use of computer technology in engineering tasks such as design, analysis, simulation, manufacture, planning, and diagnosis. CAE includes, but is not limited to, the following areas:

- Computer Aided Design (CAD) such as solid modeling and assembly modeling;

- Stress analysis of components and assemblies using Finite Element Analysis (FEA);

- Thermal and fluid flow analysis using Computational Fluid Dynamics (CFD);

- Process simulation in manufacturing such as casting, molding and forming;

- Computer Aided Manufacturing (CAM) such as graphic numerical control and SLA; and

- Optimization of products and /or processes.

The course learning objectives (CLO) of CAE (MECH-300) offered at Kettering University can be described as follows: Upon completion of the CAE course students will be able to:

- Apply the fundamental principles of Statics and Mechanics of Materials to CAD developed parts and assemblies;

- Apply modern analytical techniques to mechanical systems;

- Apply computational techniques to mechanical systems; and

- Demonstrate effective communication skills through technical presentations and reports. 
During the first three weeks of the 11-week semester CAE course, students review the techniques of solid modeling, sketching, assembly modeling, and drafting from the Freshman level Engineering Graphics course and then get instruction on advanced CAD topics including parametric part design and inter-part assembly modeling. One such example for CAD review, Figure 1 is a butterfly valve assembly. Students are required to design each of the components, the valve housing, shaft, retainer, plate, and crank. All parts are then placed in the assembly and mated properly. Advanced CAD techniques for this project include expressions and control parameters set at the assembly level so that the whole assembly can be adjusted automatically based on the main flow hole diameter, the length of the crank, and the number of fasteners.

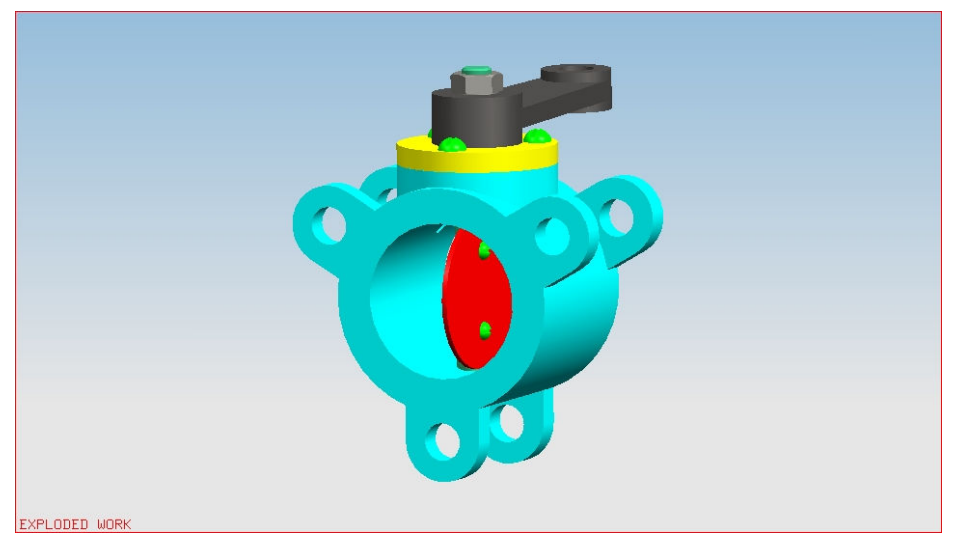

FIGURE 1 - BUTTERFLY VALVE ASSEMBLY

Over the course of the following weeks, the main educational focus is developing student skills in using Finite Element Analysis (FEA) for the design of parts and assemblies. The fundamental techniques of FEA are introduced and applied to various structural components. Students in the class perform analytical calculations based on the traditional solid mechanics analytical approaches, and compare the analytical solution to the numerical simulations developed in the FEA module of the software. FIGURE 2 shows the stress contour plot of a hook under a load. In this problem, one can see that an analytical solution can over simplify the situation when compared to results obtained from an FEA. Similar situations exist in the other assignments of the course, namely, the caster FEA (FIGURE 3) and the fixture FEA (FIGURE 4) assignments. 


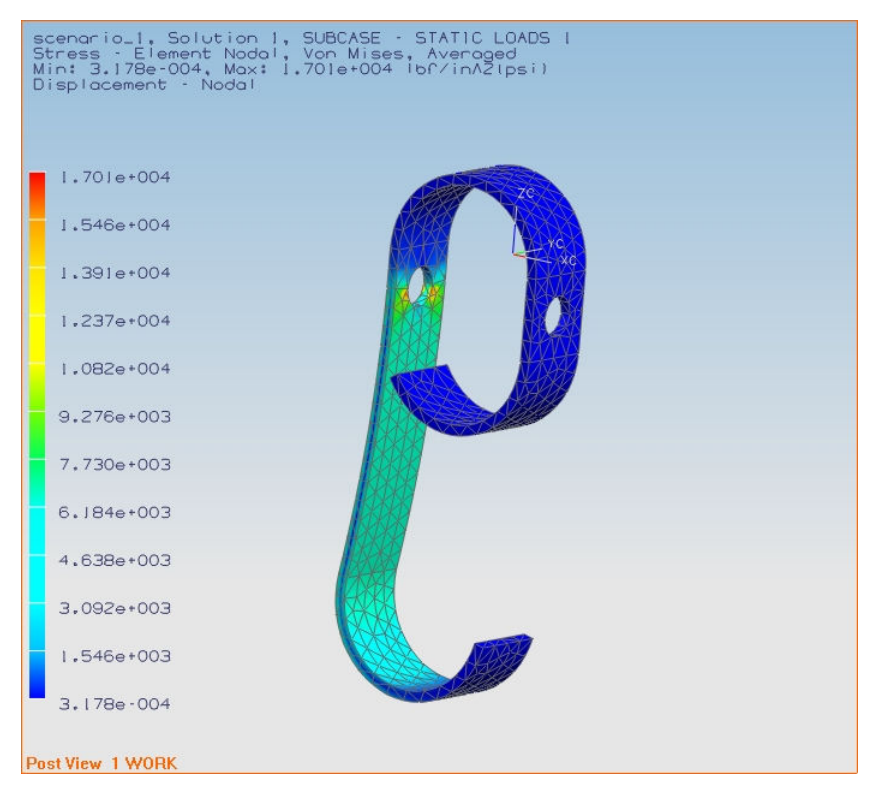

FIGURE 2 - FINITE ELEMENT ANALYSIS OF A HOOK

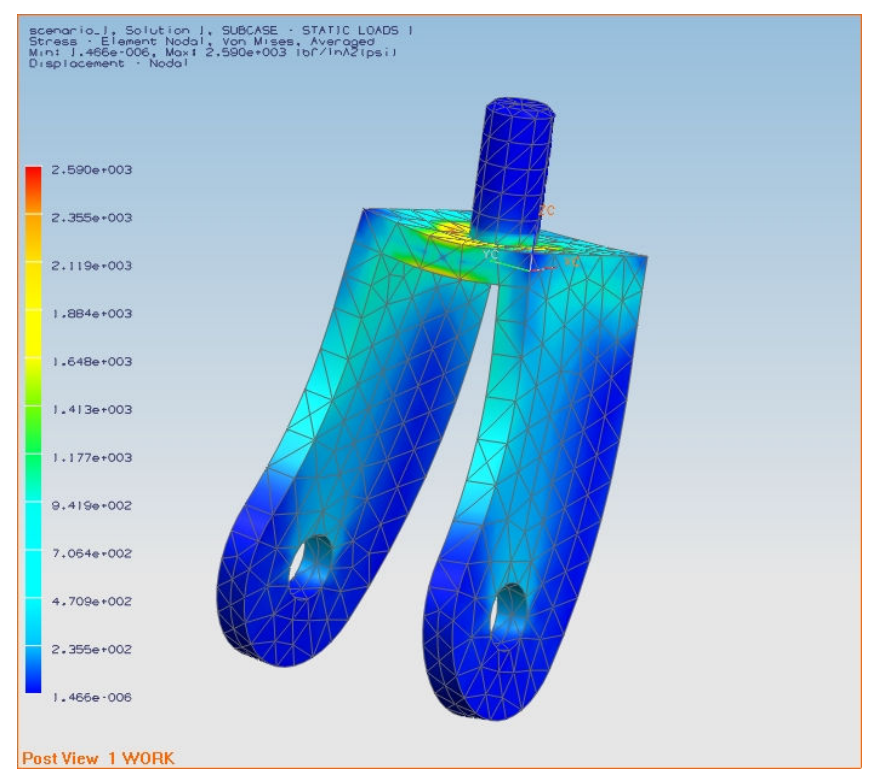

FIGURE 3 - FINITE ELEMENT ANALYSIS OF A CASTER FRAME

D
$\stackrel{0}{0}$
$\vec{D}$
$\vec{\omega}$
$\overrightarrow{0}$
$\stackrel{0}{D}$
$\vec{D}$ 


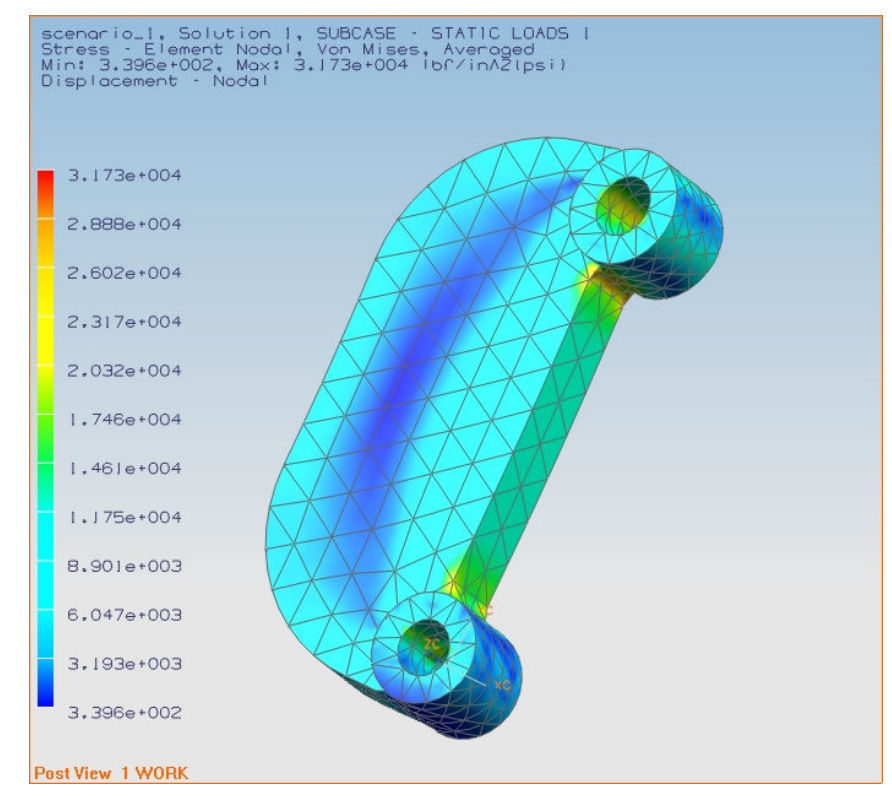

\section{FIGURE 4 - FINITE ELEMENT ANALYSIS OF A FIXTURE}

\section{Current Course Project}

Currently, an individual student term project is assigned and students work on it from the $5^{\text {th }}$ week all the way to the end of the class. The project is the design and engineering analysis of an "Impeller Assembly". The final project for the course consists of two distinct parts. Part 1 focuses on solid modeling and is based on UGS training course material ${ }^{[2]}$. Part 2 concentrates on finite element structural analysis. FIGURE 5 shows the impeller assembly designed by students during the course. The assembly is fully parameterized so students can change, for example, the size of the housing and the number of holes in the flanges of the housing, and the impeller assembly will automatically change in order to accommodate the new requirements for dimensional changes and add the proper number of bolts and nuts.
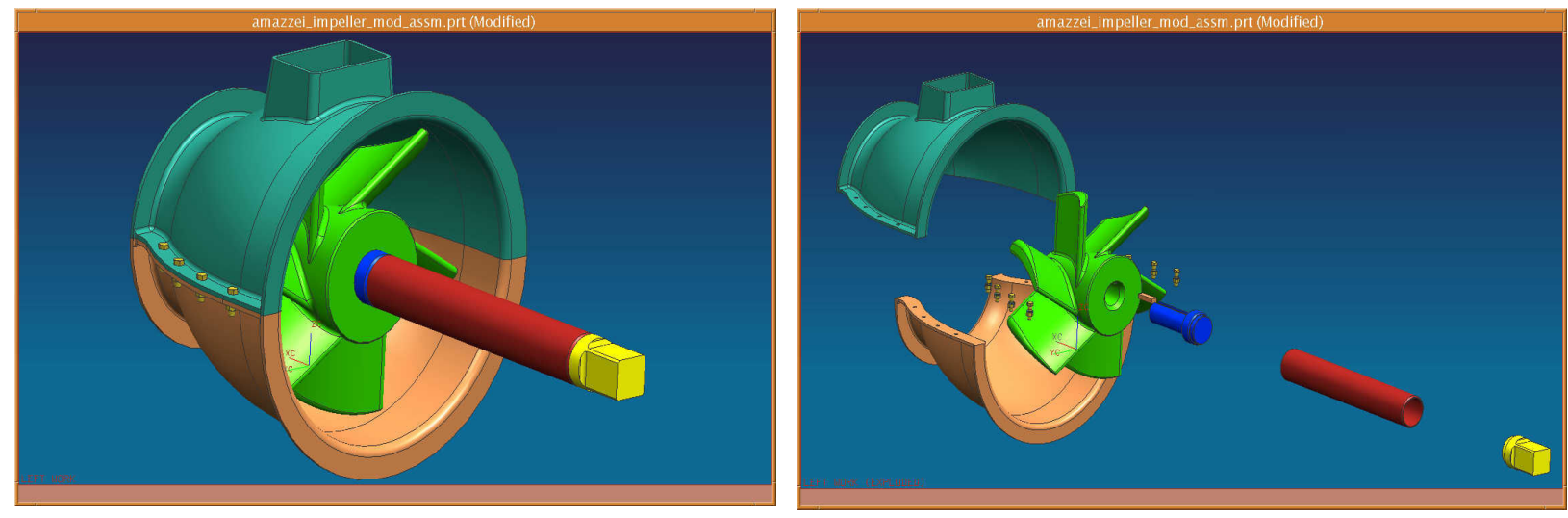

FIGURE 5 - IMPELLER ASSEMBLY (WITH EXPLODED VIEW) 
FIGURE 6 shows some results for FEA simulations of the impeller assembly. As it can be seen in the figure, students can determine the maximum levels of stresses in the parts and make a decision if a design change is needed. If a design change is indicated due to a failure to meet design specifications, the student must decide which change is suitable to meet the specification, such as a dimensional change or a change in material. Since parametric design is used, the assembly is easily adjusted to the new conditions. The completed project includes initial design, FEA results, changes made and final assembly.

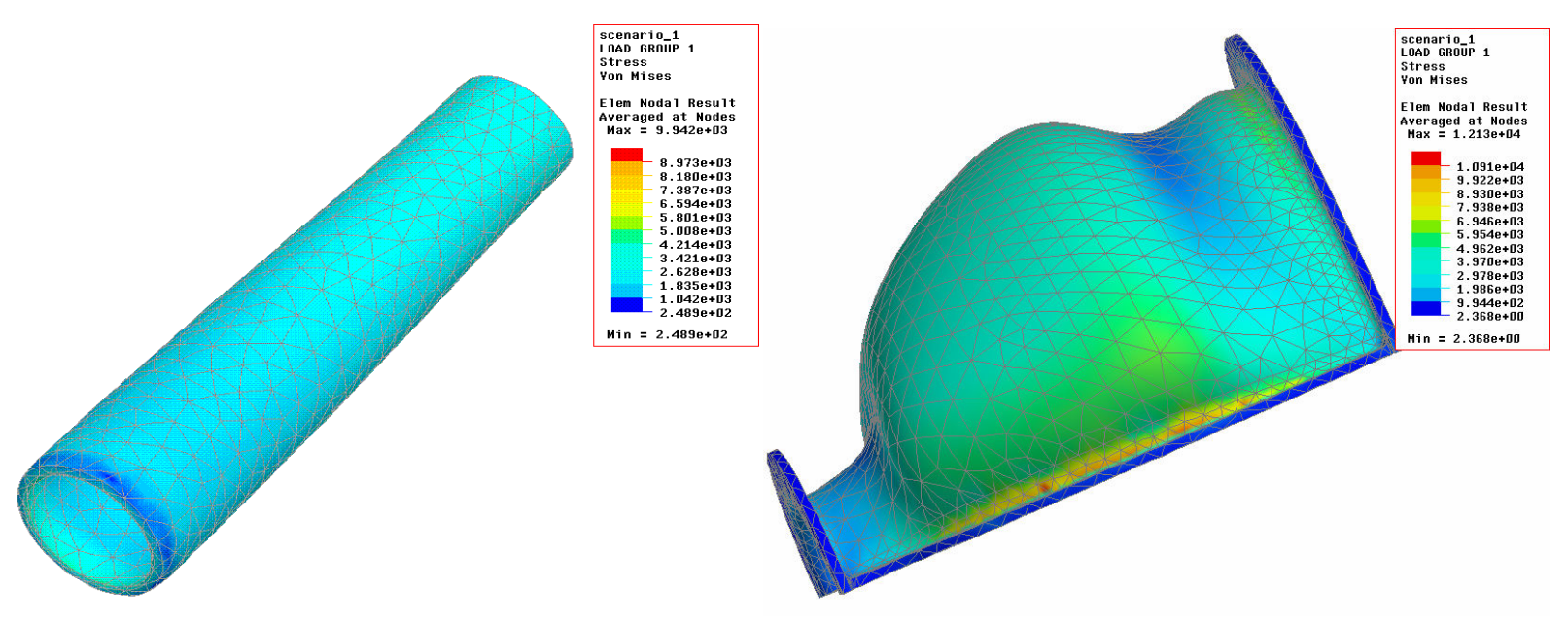

FIGURE 6 - FEA ANALYSIS FOR IMPELLER ASSEMBLY PARTS

The aforementioned individual course project has been a great exercise for the CAE students to apply the knowledge gained during the course. Yet, quite often in real world product development situations, engineers have to work concurrently as a team on the same assembly project. This raises the issue of project data management, which is currently not addressed in this course. In order to address this problem a team course project was suggested in a previous work [1]. The purpose of the proposed course project was to show how to manage and share data when working on assemblies and their related parts with other team members. Project Data Management (PDM) is used through an automotive windshield system design and analysis. Next an approach for the FEA part of this project is presented and discussed.

\section{Proposed New Project}

\section{Windshield Wiper Systems}

Automotive windshield wiper systems, in conjunction with washer systems, are used in vehicles to remove contaminants such as rain, sleet, snow, and dirt from the windshield. As shown in FIGURE 7, a typical wiper system consists of an electric motor, a linkage to transform the rotational motion from the motor to oscillatory motion, and a pair of wiper arms and blades ${ }^{[3][4]}$. The areas of the windshield that must be wiped by the wiper system are mandated by the federal motor vehicle safety standards FMVSS $104^{[5]}$. 


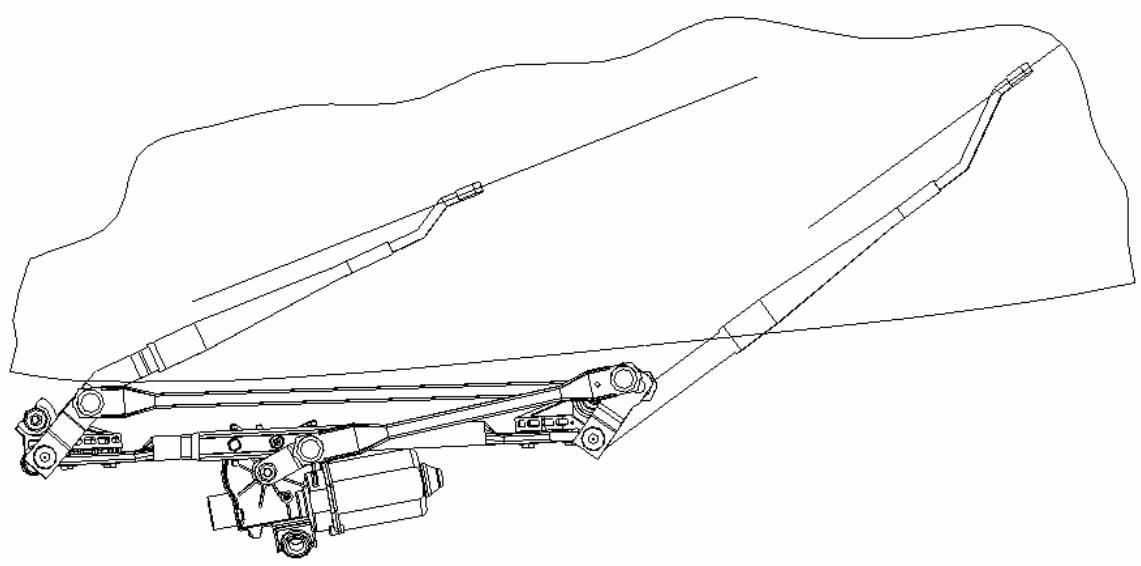

FIGURE 7 - A TYPICAL WIPER SYSTEM

The design of a typical wiper system starts with the technical specifications of the OEM car maker. Given a particular application platform, the geometry of the windshield glass is known. Based on the requirement dictated by FMVSS 104, the lengths of the wiper blades and wiping angles can be determined. Then based on wiping speed and blade-glass frictional loads, the wiper arms and blades can be designed. The linkage mechanism can be designed based on the kinematics, structural strength, wiping angle, and system packaging requirements. The electric motor can be chosen according to the energy required by the wiper system. The principles and procedures of PDM ${ }^{[6]}$ has been applied to the windshield wiper system design by Mazzei and Dong ${ }^{[1]}$. The Finite Element Analysis (FEA) of the major components will be emphasized in this work.

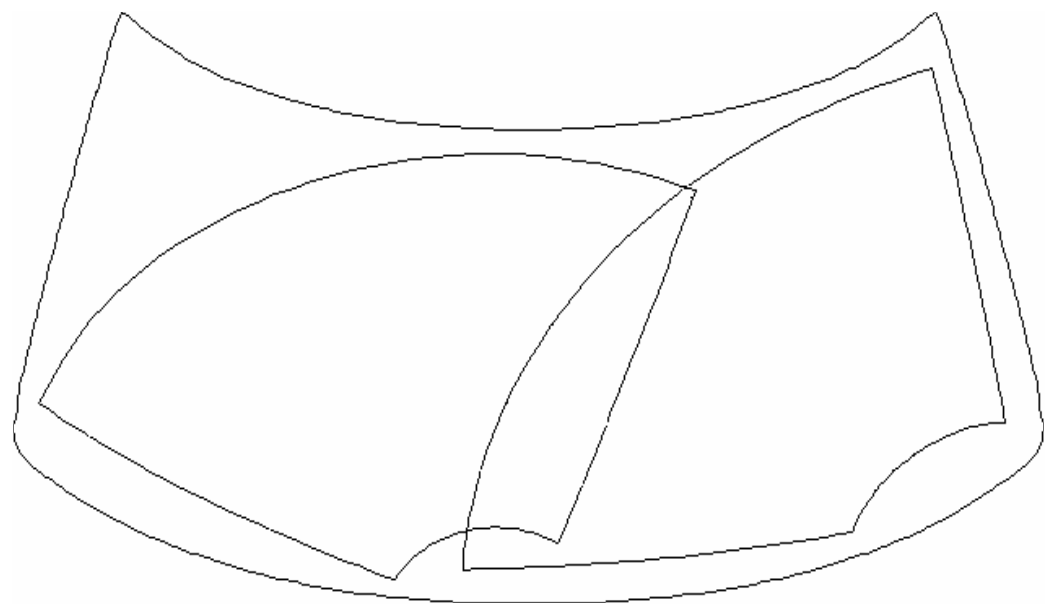

FIGURE 8 - WIPING PATTERN

The project team can be set to consist of five members including the project manager. Each member has a role defined as follows ${ }^{[1]}$ : 
1. Project Manager (PM) - creates the team library and the wiper assembly file;

2. Project Team Member 1 (PTM1) - creates and modifies the blades and arms;

3. Project Team Member 2 (PTM2) - creates and modifies the linkage members;

4. Project Team Member 3 (PTM3) - created and modifies the frame and pivot assembly;

5. Project Team Member 4 (PTM4) - creates and modifies motor and packaging interfaces.

\section{A. Arms and Blades - PTMI}

A typical wiper arm and blade structure is shown in FIGURE 9. The arm head transmits motion from the linkage and the arm retainer/rod provides the blade with a down force (commonly referred as tip force) that controls the pressure between the blade and windshield glass. The primary function of the wiper blade is to clean the windshield. As shown in FIGURE 8, the wiping pattern of the wiper system on the glass dictates the wiping angles of wiper arms/blades on both the drive side and passenger side, as well as the lengths of the blades.

For the given application, the tip load of the wiper arm is determined by the following relationship:

$$
F_{n}=L p
$$

Where

$L=$ length of the blade, $500 \mathrm{~mm}$

$p=$ pressure between the blade and the windshield glass, $0.02 \mathrm{~N} / \mathrm{m}$

The lateral force acting on the tip of the arm is

$$
F_{f}=F_{n} \mu
$$

For this calculation we use the worst case scenario, which is high friction (coefficient of friction is 2). Finite Element Analysis can be performed for the wiper arm, based upon the tip load $\left(F_{n}=10 \mathrm{~N}\right)$ and lateral force $\left(F_{f}=20 \mathrm{~N}\right)$ from equations (1) and (2). Using rolled steel with a modulus of elasticity $E=2.06 \times 10^{5} \mathrm{MPa}$ and a yield stress $\sigma_{y}=235 M P_{a}$, the Von Mises stress and displacement contour plots are depicted in FIGURE 10 and 11. The maximum stress in the wiper arm located near the arm retainer is $21.04 M P a$ which allows a safety factor of greater than 10. While maximum displacement at the tip is $0.69 \mathrm{~mm}$. Therefore this design satisfies the strength and stiffness requirements. 


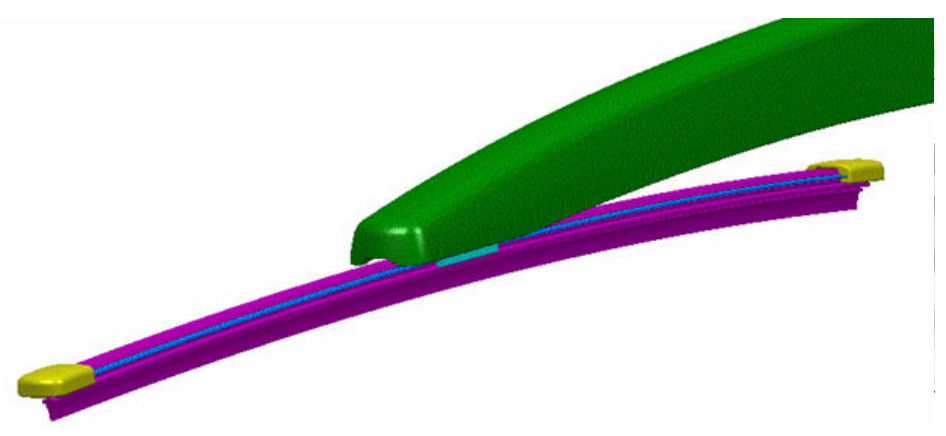

FIGURE 9 -ARM AND BLADE ASSEMBLY

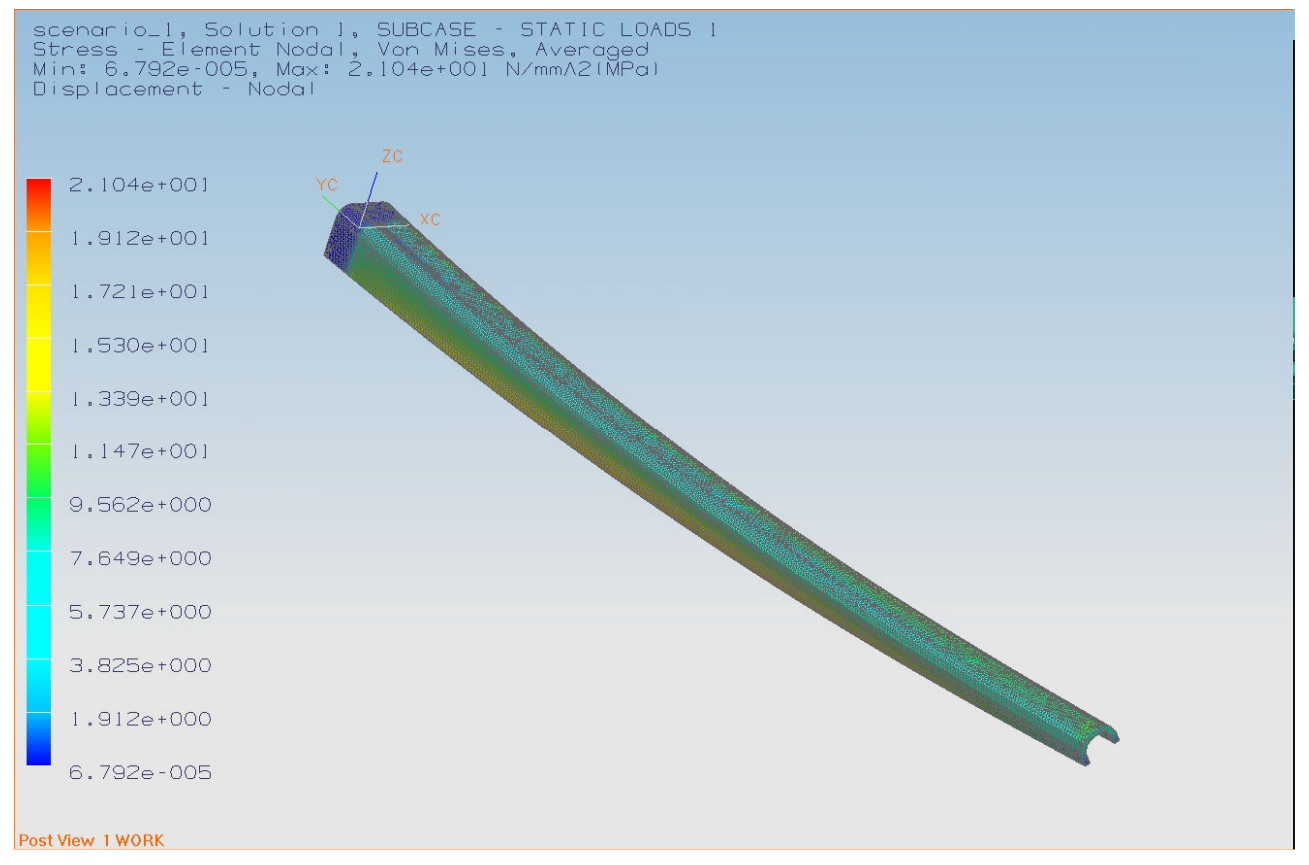

FIGURE 10 - ARM STRESS DISTRIBUTION BY FEA

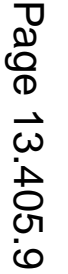




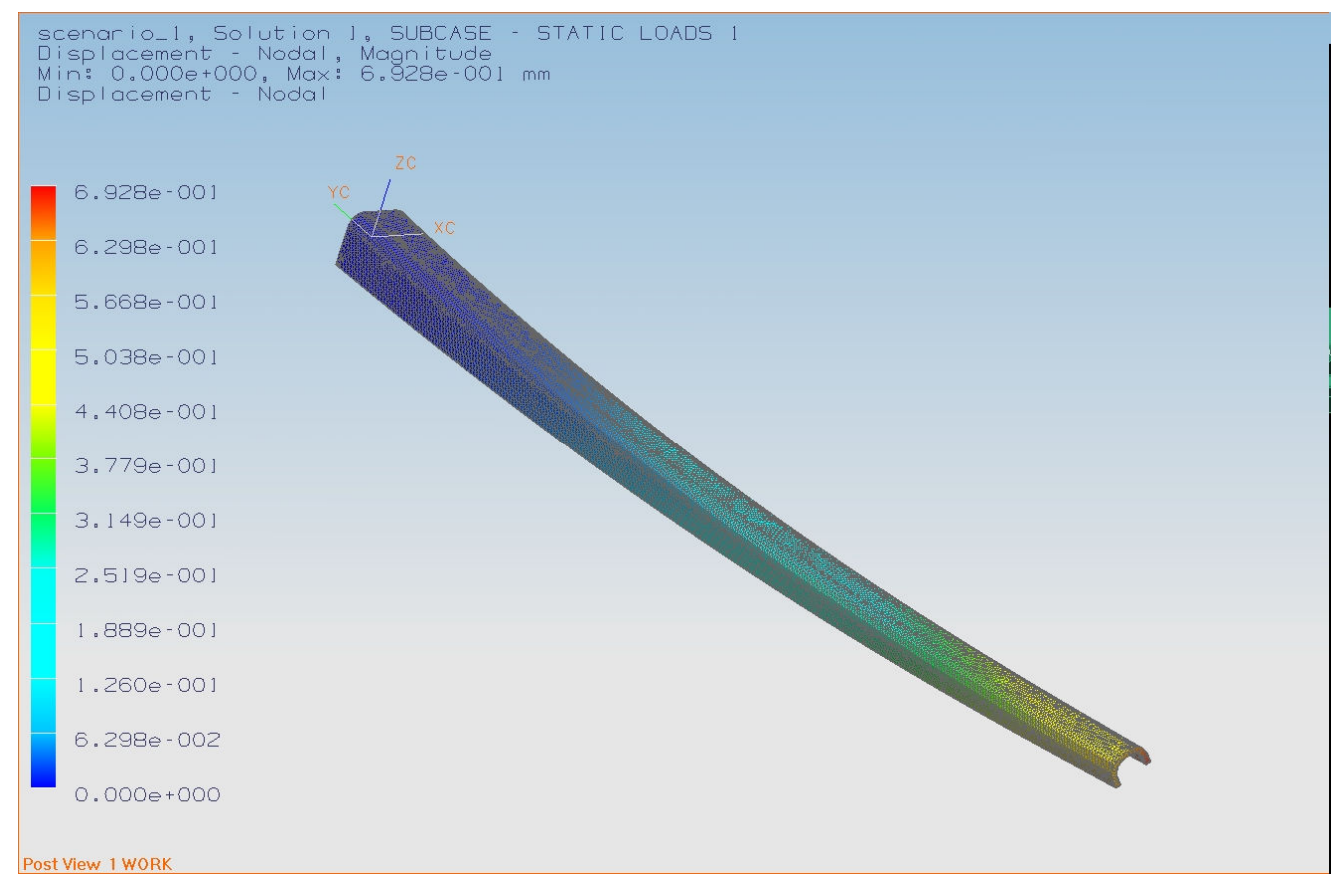

FIGURE 11 - ARM DEFORMATION BY FEA

\section{B. Linkages - PTM2}

Figure 7 shows a linkage member of the wiper system. The wiper linkage mechanism can be designed based on the kinematics of the system. The "driver" of the linkage mechanism is the crank arm which is mounted on the output shaft of the electric motor. The driver rotates continuously and transmits energy from the motor to the linkages. The "slaves" of the linkage mechanism are the levers that are fixed on the pivot shafts. Therefore the input to the system is continuous motion from the driver and the output is oscillatory motion of the pivot shafts. The linkage mechanism can be designed given the input and output. It includes two levers, one operating link, and one motor drive link. The base linkage bar is typically made of steel via a stamping process. The linkages are commonly designed to have U-shape cross-sections in order to achieve the desired structural rigidity. The spherical sockets at both ends of the linkage are over-molded plastic parts to provide for ball-socket joints. The motor drive linkage undergoes a maximum tensile load of $1000 \mathrm{~N}$ at motor stall. The stress and deformation are calculated by FEA as shown in Figure 12. 


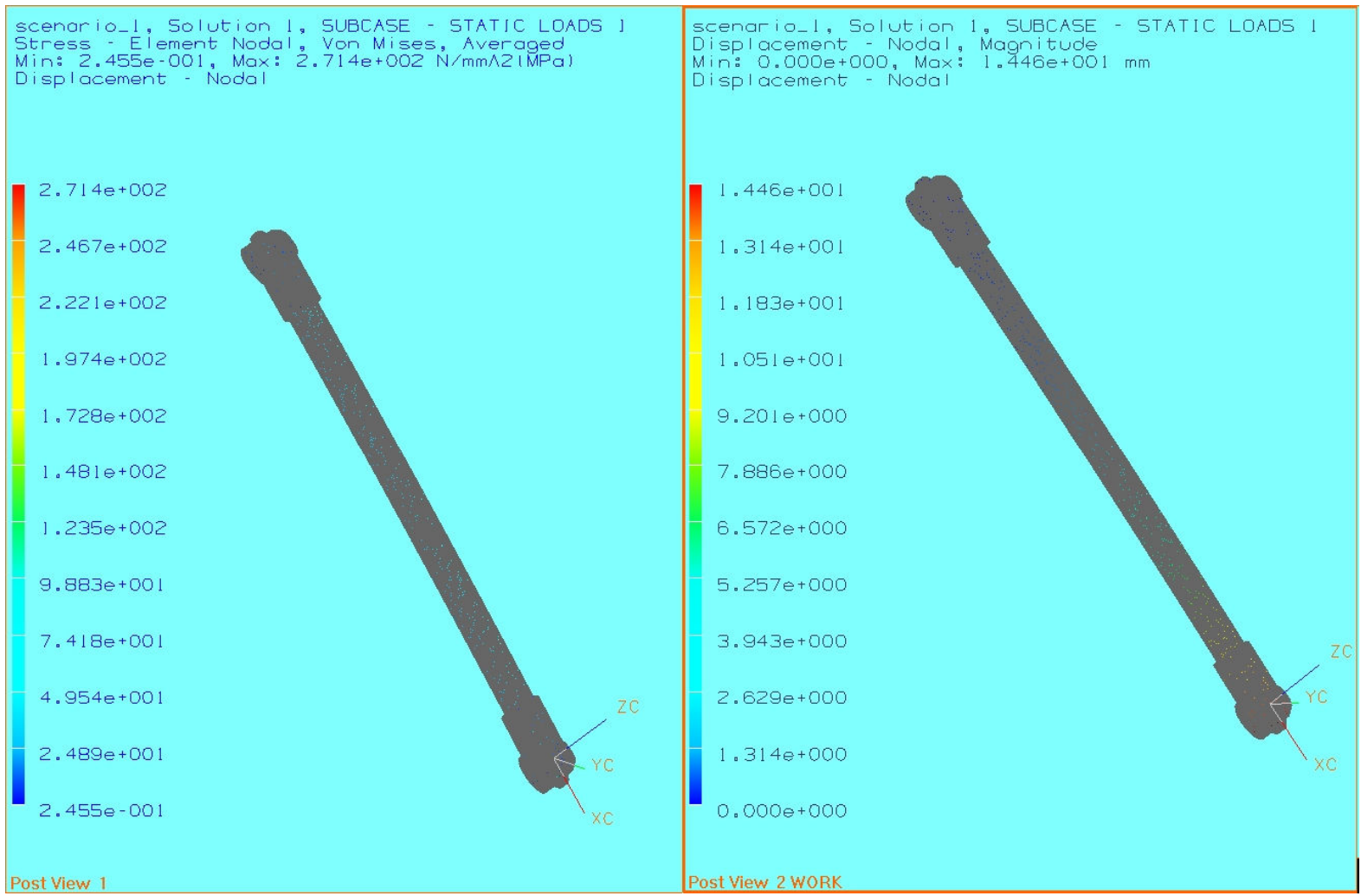

FIGURE 12 - LINKAGE STRESS AND DEFORMATION BY FEA

\section{Pivot Shaft - PTM3}

The wiper arm and the lever are mounted on the pivot shaft that is located in the pivot housing assembly (Figure 13). The pivot housing assembly includes grommet, retainer, washer, O-ring, bearings, spring washers, pivot shaft, lever and ball stud. The components in the pivot housing assembly must be able to withstand the load of the wiper system. The wiper system is mounted onto the vehicle though the mounting holes on the pivot housing. Grommets are commonly used to provide certain level of system compliance under load and reduce noise transmitted to the vehicle.

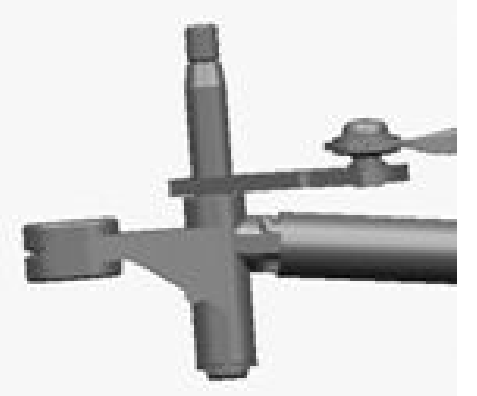


The pivot shaft is the most critical component in the pivot shaft assembly, because the wiper arm and blade assembly is mounted on the top and the lever is in connected in the middle. If the pivot shaft fails, the whole wiper system will lose its performance, even its function. Figure 14 depicts the pivot shaft FEA model. The wiper arm is mounted on the cone and fastened by the arm nut. Therefore a torque of $T=F_{f} L_{a}=20 \mathrm{~N} \times 500 \mathrm{~mm}=1000 \mathrm{Nmm}$ ( $L_{a}$ is the arm length) is applied at the arm mounting location. At the lever mounting location, a force of $F=1000 \mathrm{~N}$ is applied corresponding to the lever tensile load. Constraints are applied at the bottom portion of the pivot shaft corresponding to the sleeve bearing, where the rotation about $Z$ axis and translation in $\mathrm{Z}$ direction are free while all other degrees of freedom are fixed.

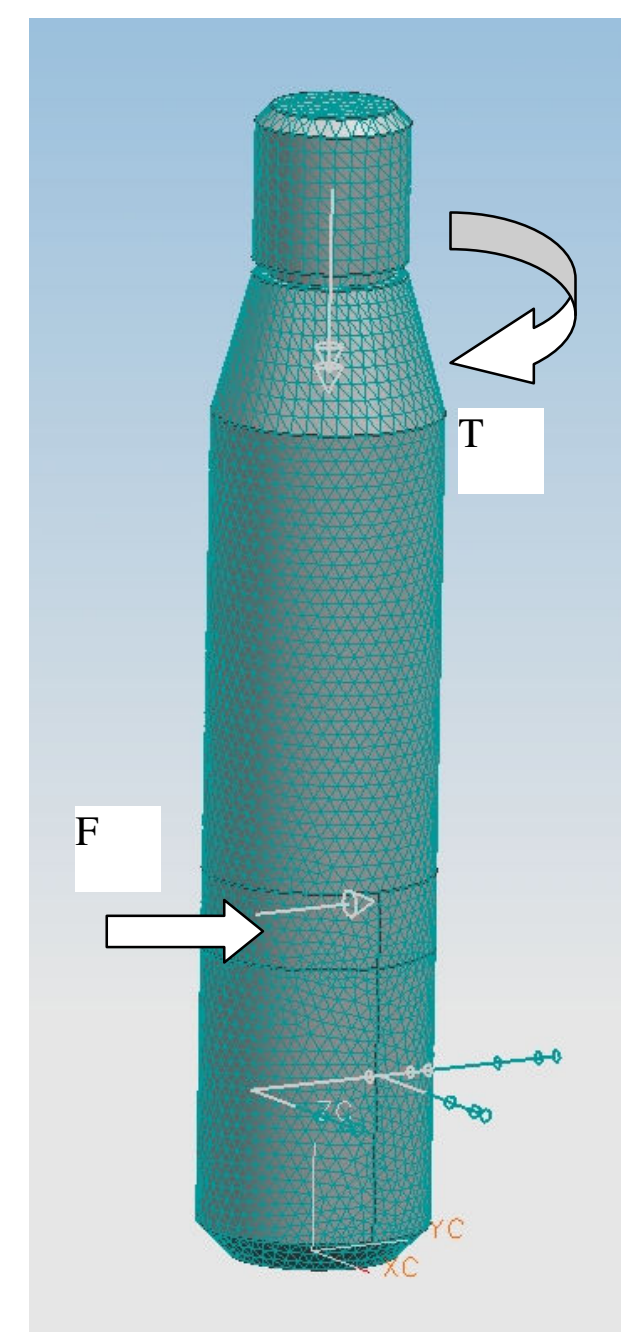

FIGURE 14 - PIVOT SHAFT FEA MODEL

FIGURE 15 shows the stress and displacement distributions. Given the same material properties as the wiper arm, it is seen that this design is safe. 


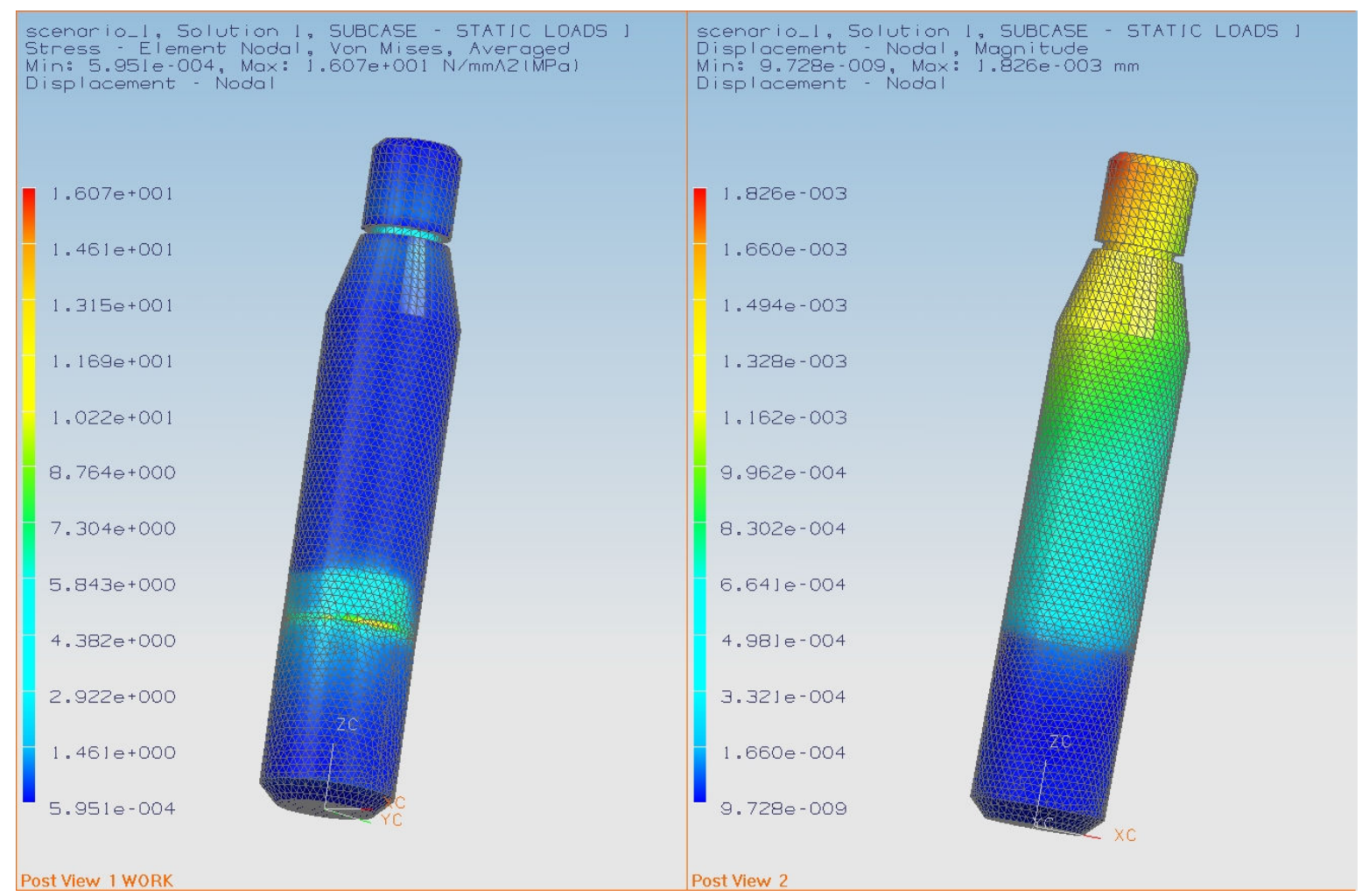

FIGURE 15 - PIVOT SHAFT STRESS AND DEFORMATION BY FEA

\section{Conclusions}

The proposed team project for the CAE course addresses Project Data Management (PDM) through an automotive windshield system design and analysis. The purpose of the course project is to show how to manage and share data when working on assemblies and their related parts with other team members. Each project team has five members and a set-up with a "configured project" including Roles, States, Approval Process, Library and Cataloge. Each team member is responsible for several parts design or analysis. The FEA of the wiper arm, linkage, and pivot shaft are presented as examples of virtual prototyping. Through data sharing and iteration of all team members, the wiper system assembly is optimized to meet given technical specifications.

\section{References}

[1] A. Mazzei and Y. Dong, Development of CAE Course Project Focusing On Data Management Through Windshield Wiper System Design, Paper \#AC 2007-304, ASEE Conference in Honolulu, Hawaii from June 24-27 2007

[2] UGS Corp, Design Application Using NX - Workbook, MT10055-W-NX4, 2006 (WWW.ugs.com)

[3] Y. Dong, J. Penrod, Use of a Designed Experiment to Determine the Optimal Method to Join InjectionMolded Parts to Pultrusions, SAE Technical Paper Series, 2006-01-3575 (2006).

[4] H. C. Buchanan and Y. Dong, Windshield Wiping System, United States Patent, US 6,148,470, Valeo Electrical Systems, Inc. (2000).

[5] FMVSS 571-104, 49 CFR, Federal Motor Vehicle Safety Standards; Windshield Wiping and Washing Systems, National Highway Traffic Safety Administration, DOT, USA.

[6] Eletronic Data Systems Corporation, Data Management User's Guide, EDS, 2003 